\title{
Effects of Hole Transport and Injection Layers on the Efficiency of Flexible Organic Light-emitting Diodes
}

\author{
Fa-Ta Tsai, Ching-Kong Chao, Sheng-Da Cai, Rwei-Ching Chang
}

\begin{abstract}
The efficiency of organic light-emitting diodes (OLEDs) strongly depends on the mobility of electric holes in the organic materials. To improve the performance of flexible OLEDs, various thicknesses of hole injection layers and hole transporting layers in the flexible OLEDs were studied in this work. The PEDOT:PSS hole injection layer was deposited on the ITO coated PET substrate by spin coating at the first, and then deposited the NPB hole transporting layer, $\mathrm{Alq}_{3}$ emitting layer, and aluminum cathode by thermal evaporation. The OLED component was covered with a PET film and packaged by UV glue in the final. The luminance, chromaticity coordinate, and life time of the flexible OLEDs were tested, where the thickness effects of the PEDOT:PSS and NPB on the OLED performance were also studied. The result showed that the flexible OLED stacked as PET /Al $200 \mathrm{~nm} / \mathrm{Alq}_{3} 100 \mathrm{~nm} / \mathrm{NPB} 40 \mathrm{~nm}$ /PEDOT:PSS $130 \mathrm{~nm} /$ /ITO /PET had the best performance with $2640.7 \mathrm{~cd} / \mathrm{m}^{2}$ at $10 \mathrm{~V}$.
\end{abstract} layer.

Keywords - OLED; flexible; hole injection layer; hole transport

\section{Introduction}

Due to the advantages of high brightness and contrast, lower power consumption, wider viewing angle, faster response time, easy color tuning, thinner, and lighter, organic light emitting diodes (OLEDs) draw great attention. OLED displays based on glass substrates have been used in smart phones, smart pads, and TVs. Moreover, flexible OLEDs have attracted much attention because of high mechanical flexibility [1-3]. However, to achieve commercial standard, the device lifetime and luminance efficiency of the devices still needs to be improved.

To improve the performance of OLEDs, various attempts have been taken in the fabrication processes. One of the promising methods is to increase the efficiency of the electron transportation between the organic materials [4-6]. Due to its high optical transparency and electrical conductivity, ITO is the most widely used transparent anode for OLEDs. The performance of OLEDs is highly affected by the hole injection ability of the ITO anode. Hole injection layers (HIL) are inserted between the hole transporting layer (HTL) and the ITO anode to improve OLED performance by decreasing the energy level between the HTL and anode. Many HILs have been studied [7-13] in which Poly(3,4-ethylenedioxythiophene)

Fa-Ta Tsai, Ching-Kong Chao

Dep. of Mechanical Engineering, National Taiwan University of Science and Technology, Taiwan

Sheng-Da Cai, Rwei-Ching Chang

Dep. of Mechanical and Computer-Aided Engineering, St. John's University, Taiwan poly(styrenesulfonate) (PEDOT:PSS) was reported as a good hole injection material.

In this work, the effects of various thicknesses of HIL and HTL on the performance of the OLEDs were studied. Various thicknesses of PEDOT:PSS films were deposited on ITO PET substrates by spin coating. And then, the other organic emitting layers were deposited on the top of the PEDOT:PSS films by thermal evaporation to finish the OLED devices. The luminance of the OLEDs with various HTL and HIL thicknesses were tested.

\section{Specimen Preparation}

The structure of the OLED is shown in Fig. 1, where a flexible PET substrate, an ITO anode, a PEDOT:PSS (Clevios AI4083) hole injecting layer (HIL), a NPB hole transporting layer (HTL), an $\mathrm{Alq}_{3}$ emitting layer (EL), an aluminum cathode, and a PET cover were stacked in sequence. The ITO-coated PET substrate with size $300 \times 200 \times 0.175 \mathrm{~mm}$ was treated by standard cleaning procedure including ultrasonic bath and oxygen plasma before deposition. To fabricate the OLED, a PEDOT:PSS HIL was deposited on the ITO/PET substrate by spin coating at the first. The film thickness was controlled by the spin speed, where 110 , 130 , and $150 \mathrm{~nm}$ was spun with 6000,5500 , and $5000 \mathrm{rpm}$ for 30 sec, respectively. The specimen was followed by drying process at $70{ }^{\circ} \mathrm{C}$ for $10 \mathrm{~min}$. And then, the NPB HTL and $\mathrm{Alq}_{3} \mathrm{EL}$ were thermally evaporated with $1 \AA / \mathrm{s}$ deposition rate. And, an aluminum cathode was successively evaporated. Finally, the device was covered with a PET substrate, packaged by UV glue, and cured by UV light for $1 \mathrm{hr}$. Various thicknesses of the PEDOT:PSS HIL, NPB HTL, and $\mathrm{Alq}_{3}$ EL were considered.

The thicknesses of each layer were confirmed by a Kosaka ET4000 surface profiler. The luminance and chromaticity of the OLEDs is measured by UV/VIS/NIR spectrophotometer (BWTEK BTC112) in the ambient air at room temperature.

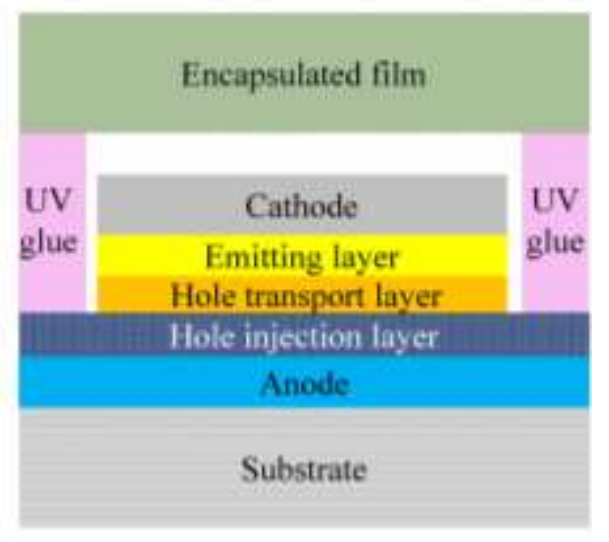

Figure 1. Structure of OLED. 


\section{Results and Discussion}

The luminance of OLEDs at applied voltage $0 \sim 10 \mathrm{~V}$ are shown in Fig. 2, where the $\mathrm{Alq}_{3}$ EL and PEDOT:PSS HIL thicknesses are fixed at 100 and $130 \mathrm{~nm}$, and three thicknesses of the NPB HTL, 20, 40, $60 \mathrm{~nm}$, are considered. The results show that the OLEDs work as the applied voltage higher than $4 \mathrm{~V}$, and the luminance increases quickly as the voltage increases. The results also show the case of $40 \mathrm{~nm}$ NPB presents the highest luminance $2640.7 \mathrm{~cd} / \mathrm{m}^{2}$ at $10 \mathrm{~V}$, the case of $60 \mathrm{~nm} \mathrm{NPB}$ is $1948.5 \mathrm{~cd} / \mathrm{m}^{2}$, and $20 \mathrm{~nm} \mathrm{NPB}$ has the lowest luminance $1752.6 \mathrm{~cd} / \mathrm{m}^{2}$ at $10 \mathrm{~V}$. It indicates the optimal thickness arrangement of HIL, HTL, and EL in the OLED is needed to improve the electron transportation by decreasing the energy gap between the stacked layers.

Fig. 3 shows the corresponding images of OLEDs at $10 \mathrm{~V}$, where NPB is (a) 20, (b) 40, and (c) $60 \mathrm{~nm}$ with fixed $\mathrm{Alq}_{3}$ and PEDOT:PSS. Each luminant area is $2 \times 2 \mathrm{~mm}$, which indicates the case (b) with $40 \mathrm{~nm}$ NPB presents the highest luminance.

Fig. 4 shows the corresponding current density of OLEDs at applied voltage $0 \sim 10 \mathrm{~V}$. It shows the OLED with $40 \mathrm{~nm}$ NPB presents the highest current density, and that with $20 \mathrm{~nm}$ NPB is the lowest. The results of current density are consistent with the luminance results shown in Fig. 2.

The life time of the OLEDs are shown in Fig. 5, where the OLED with $\mathrm{Alq}_{3} 100 \mathrm{~nm} / \mathrm{NPB} 40 \mathrm{~nm} / \mathrm{PEDOT}$ :PSS $130 \mathrm{~nm}$ is discussed. Fig. 5 compares the luminance of the OLEDs between 0 hour and after 24 hours usage. It shows the luminance is $2640.7 \mathrm{~cd} / \mathrm{m}^{2} @ 10 \mathrm{~V}$ at the begin (0 hour), and the luminance decays to $1860.9 \mathrm{~cd} / \mathrm{m}^{2} @ 10 \mathrm{~V}$ after 24 hours usage. The result indicates the luminance decays $70.47 \%$ after 24 hrs.

The luminance at $10 \mathrm{~V}$ and chromaticity coordinate for the above three cases are listed in Table 1. It illustrates the case (a) has the lowest luminance $1752.6 \mathrm{~cd} / \mathrm{m}^{2}$ at $10 \mathrm{~V}$, and case (b) presents the highest $2640.7 \mathrm{~cd} / \mathrm{m}^{2}$. It also indicates the chromaticity coordinate of case (b) is $(0.34,0.49)$, and cases (a) and (c) are $(0.33,0.51)$, which are consistent with the original color of the $\mathrm{Alq}_{3}$ emitting layer.

For various thicknesses of PEDOT:PSS HIL, NPB HTL, and $\mathrm{Alq}_{3}$ EL, similar patterns of luminance, current density, and luminance decay were found. In summary, the luminance of the OLEDs at $10 \mathrm{~V}$ with various thicknesses of PEDOT:PSS, $\mathrm{NPB}$, and $\mathrm{Alq}_{3}$ are listed in Table 2. The luminance wildly ranges from 121 to $2640 \mathrm{~cd} / \mathrm{m}^{2}$, which indicates the luminance of OLEDs strongly depend on the thickness of the organic layers. It illustrates that the OLEDs with $130 \mathrm{~nm}$ PEDOT:PSS and $100 \mathrm{~nm} \mathrm{Alq}{ }_{3}$ presents the higher luminance than other case, where $40 \mathrm{~nm} \mathrm{NPB}$ is the higher one than the other thickness. Overall, the combination of OLED with $130 \mathrm{~nm}$ PEDOT:PSS, $100 \mathrm{~nm} \mathrm{Alq}$, and $40 \mathrm{~nm} \mathrm{NPB}$ presents the highest luminance of $2640.7 \mathrm{~cd} / \mathrm{m}^{2}$.

The summary of current density of the OLEDs at $10 \mathrm{~V}$ with various thicknesses of PEDOT:PSS, NPB, and $\mathrm{Alq}_{3}$ are listed in Table 3. The results consist with the luminance distribution listed in Table 2. Similarly, the highest current density is
$249.829 \mathrm{~mA} / \mathrm{cm}^{2} @ 10 \mathrm{~V}$ occurred at $130 \mathrm{~nm}$ PEDOT:PSS, 100 $\mathrm{nm} \mathrm{Alq}_{3}$, and $40 \mathrm{~nm}$ NPB.

The summary of luminance decay of the OLEDs with various thicknesses of PEDOT:PSS, NPB, and $\mathrm{Alq}_{3}$ are listed in Table 4. In this work, the luminance decay is defined as the ratio of the luminance after 24 hours usage to the luminance at the OLEDs finished moment (0 hour). A narrow range from 65 to $74 \%$ are shown, which indicates the life time of the OLEDs is more dependent on the encapsulation than the electric hole mobility.

In general, HIL are inserted between the HTL and the anode to improve OLED performance by decreasing the energy level between the HTL and anode. Moreover, thicker HTL and EL can increase the luminance of OLEDs. However, the device applied voltage will increases as the HTL and EL thickness increase, resulting in higher energy consumption. Therefore, it is needed to design an optimal arrangement of the stacked layer thicknesses of OLEDs.

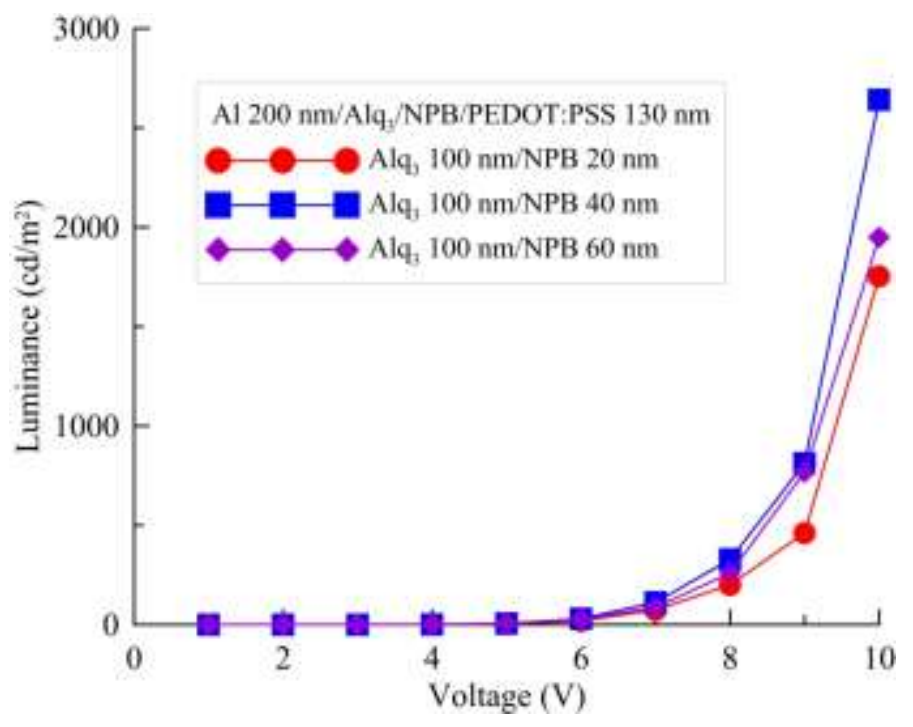

Figure 2. Luminance of OLEDs with various thicknesses of NPB.

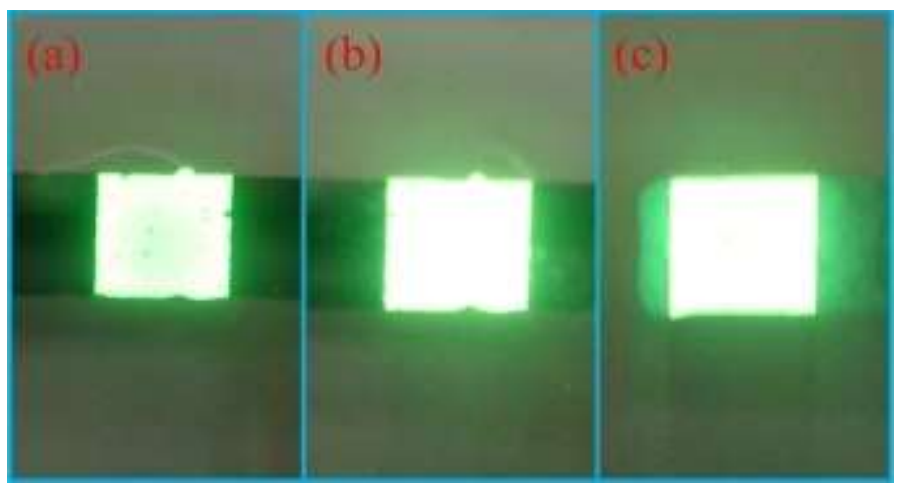

Figure 3. Images of OLED (a) Alq $100 \mathrm{~nm} / \mathrm{NPB} 20 \mathrm{~nm} / \mathrm{PEDOT}$ :PSS $130 \mathrm{~nm}$ (b) $\mathrm{Alq}_{3} 100 \mathrm{~nm} / \mathrm{NPB} 40 \mathrm{~nm} / \mathrm{PEDOT}: \mathrm{PSS} 130 \mathrm{~nm}$ (c) $\mathrm{Alq}_{3} 100 \mathrm{~nm} / \mathrm{NPB} 60$ $\mathrm{nm} / \mathrm{PEDOT}: \mathrm{PSS} 130 \mathrm{~nm}$. 
Proc. of The Second Intl. Conf. On Advances in Civil, Structural and Mechanical Engineering - ACSM 2015 Copyright $(\odot$ Institute of Research Engineers and Doctors, USA .All rights reserved.

ISBN: 978-1-63248-074-3 doi: 10.15224/ 978-1-63248-074-3-30

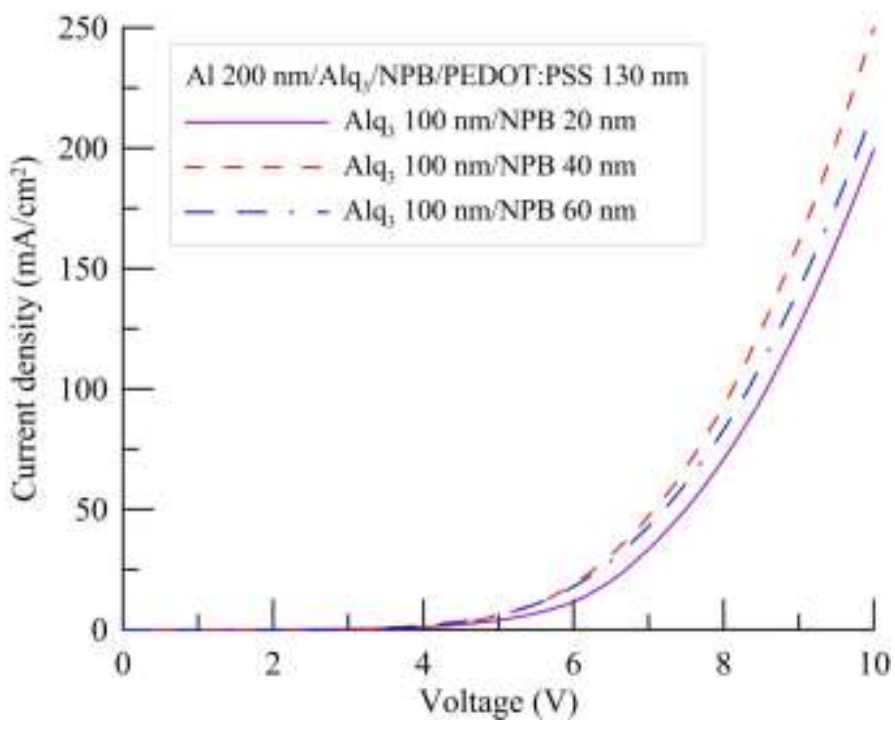

Figure 4. Current density of OLEDs with various thicknesses of NPB.

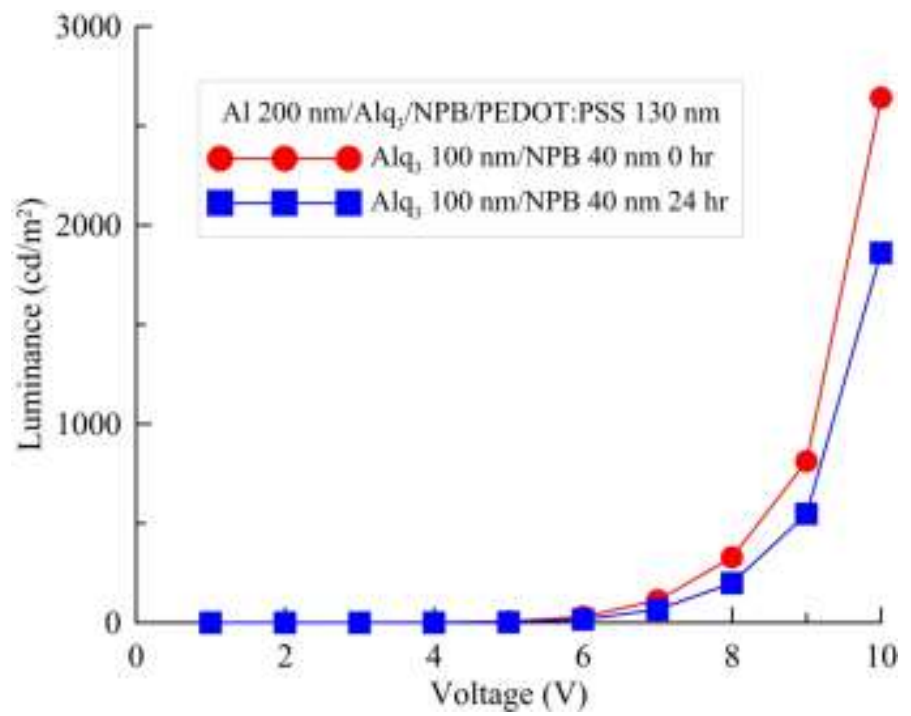

Figure 5. Luminance of OLEDs with $\mathrm{Alq}_{3} 100 \mathrm{~nm} / \mathrm{NPB} 40 \mathrm{~nm} / \mathrm{PEDOT}: \mathrm{PSS}$ $130 \mathrm{~nm}$ at 0 and $24 \mathrm{hrs}$.

Table 1. Luminance and chromaticity coordinate of OLEDs with various NPB thichnesses, where $\mathrm{Alq}_{3}=100 \mathrm{~nm}$, PEDOT:PSS=130 nm

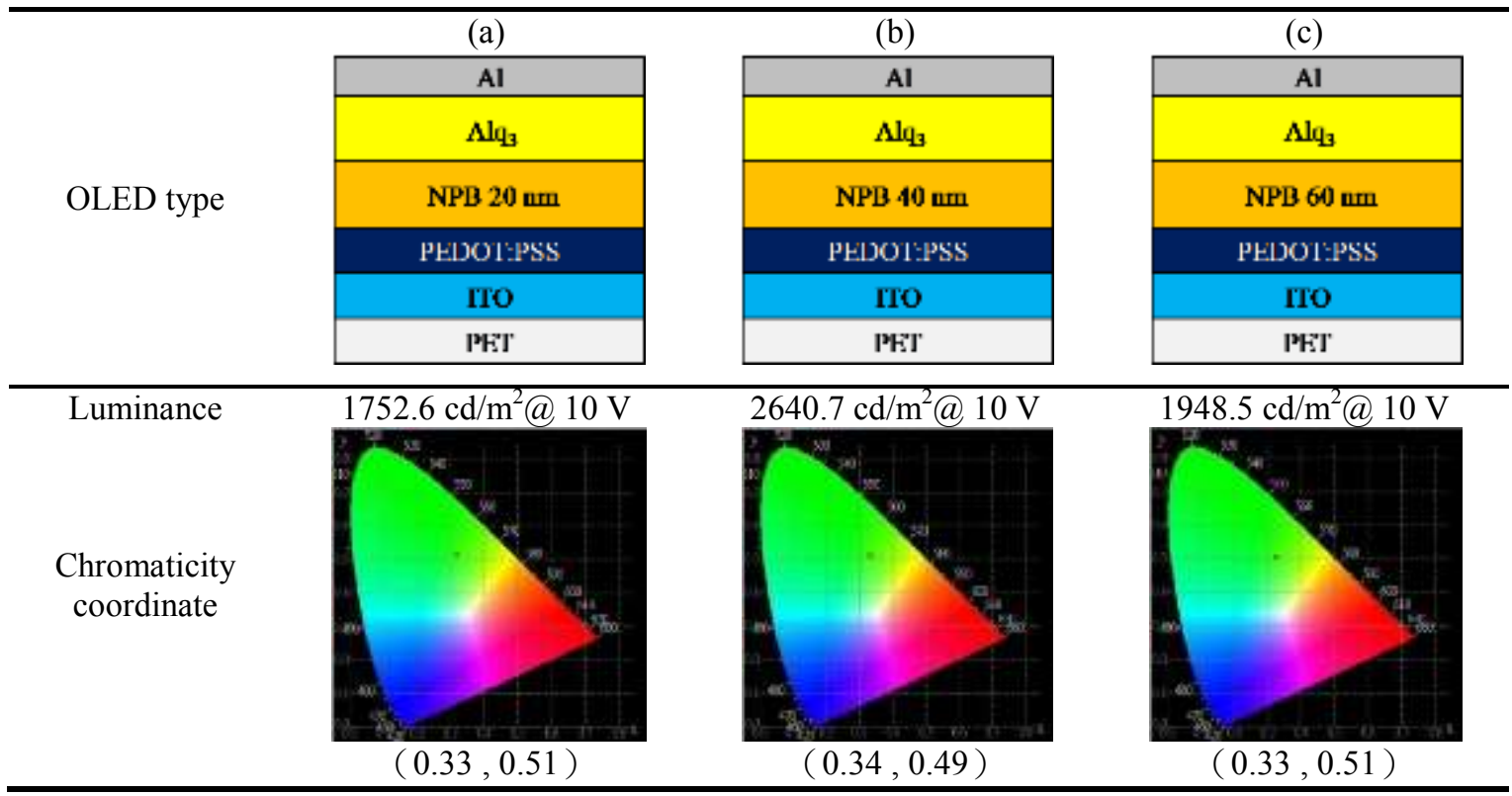

Table 2. Summary of luminance of OLEDs with various thicknesses of HIL, EL and HTL (cd/m²@10 V)

\begin{tabular}{ccccc}
\hline $\begin{array}{c}\text { PEDOT:PSS HIL } \\
(\mathrm{nm})\end{array}$ & $\begin{array}{c}\mathrm{Alq}_{3} \mathrm{EL} \\
(\mathrm{nm})\end{array}$ & 20 & 40 & 60 \\
\cline { 3 - 5 } & 20 & $121.18_{-21.62}^{+19.35}$ & $173.94_{-16.97}^{+20.41}$ & $127.75_{-18.26}^{+18.84}$ \\
70 & 40 & $465.75_{-16.08}^{+10.72}$ & $559.45_{-20.49}^{+25.41}$ & $434.59_{-27.85}^{+21.43}$ \\
90 & 60 & $783.75_{-32.76}^{+42.71}$ & $1097.9_{-52.5}^{+44.0}$ & $651.23_{-54.29}^{+30.42}$ \\
110 & 80 & $1125.9_{-19.4}^{+30.5}$ & $2123.4_{-43.4}^{+33.7}$ & $1224.3_{-23.0}^{+3.3}$ \\
130 & 100 & $1752.6_{-29.6}^{+38.8}$ & $2640.7_{-34.5}^{+52.9}$ & $1948.5_{-51.0}^{+48.8}$ \\
150 & 120 & $1455.0_{-13.2}^{+32.7}$ & $1688.2_{-28.7}^{+25.2}$ & $1210.0_{-54.3}^{+43.7}$ \\
\hline
\end{tabular}

Table 3. Summary of current density of OLEDs with various thicknesses of HIL, EL and HTL (mA/cm²@10 V) 
Proc. of The Second Intl. Conf. On Advances in Civil, Structural and Mechanical Engineering - ACSM 2015 Copyright (C) Institute of Research Engineers and Doctors, USA .All rights reserved.

ISBN: 978-1-63248-074-3 doi: 10.15224/ 978-1-63248-074-3-30

\begin{tabular}{ccccc}
\hline \multirow{2}{*}{$\begin{array}{c}\text { PEDOT:PSS HIL } \\
(\mathrm{nm})\end{array}$} & $\begin{array}{c}\mathrm{Alq}_{3} \text { EL } \\
(\mathrm{nm})\end{array}$ & 20 & 40 & 60 \\
\cline { 3 - 5 } & 20 & $9.803_{-0.690}^{+0.203}$ & $12.126_{-0.047}^{+0.763}$ & $6.997_{-0.827}^{+0.885}$ \\
70 & 40 & $58.484_{-0.637}^{+2.588}$ & $76.251_{-1.049}^{+0.084}$ & $55.764_{-0.567}^{+0.948}$ \\
90 & 60 & $119.939_{-1.292}^{+0.871}$ & $132.039_{-7.502}^{+0.588}$ & $98.878_{-1.858}^{+1.174}$ \\
110 & 80 & $134.988_{-0.513}^{+1.902}$ & $237.228_{-1.393}^{+1.202}$ & $145.598_{-1.201}^{+0.169}$ \\
130 & 100 & $199.404_{-1.962}^{+1.298}$ & $249.829_{-0.784}^{+0.166}$ & $216.024_{-0.474}^{+0.116}$ \\
150 & 120 & $156.690_{-0.743}^{+0.847}$ & $193.773_{-1.043}^{+2.359}$ & $142.039_{-1.449}^{+0.668}$ \\
\hline
\end{tabular}

Table 4. Summary of luminance decay of OLEDs with various thicknesses of HIL, EL and HTL (\%@10 V).

\begin{tabular}{ccccc}
\hline PEDOT:PSS HIL & $\mathrm{Alq}_{3}$ EL & \multicolumn{3}{c}{ NPB HTL $(\mathrm{nm})$} \\
\cline { 3 - 5 }$(\mathrm{nm})$ & $(\mathrm{nm})$ & 20 & 40 & 60 \\
\hline 50 & 20 & 66.81 & 65.14 & 69.52 \\
70 & 40 & 70.95 & 65.75 & 68.18 \\
90 & 60 & 67.24 & 72.55 & 73.45 \\
110 & 80 & 70.20 & 71.15 & 65.65 \\
130 & 100 & 67.35 & 70.47 & 74.73 \\
150 & 120 & 74.93 & 69.69 & 66.47 \\
\hline
\end{tabular}

\section{Conclusions}

Effects of HIL and HTL on organic light-emitting diodes coating on flexible PET substrates were studied. Considering various thickness PEDOT:PSS hole injection layer and NPB hole transporting layer, the luminance of the OLEDs were tested. The results showed that the flexible OLED stacked as $\mathrm{Alq}_{3} 100 \mathrm{~nm}$ /NPB $40 \mathrm{~nm} / \mathrm{PEDOT}: P S S 130 \mathrm{~nm}$ has the best performance with $2640.7 \mathrm{~cd} / \mathrm{m}^{2}$ at $10 \mathrm{~V}$. To balance the emitting performance and energy consumption, it is needed to design an optimal arrangement of the stacked layer thicknesses of OLEDs. Moreover, the 24 hours luminance tests indicated that the life time of the OLEDs is more dependent on the encapsulation than the electric hole mobility.

\section{Acknowledgment}

The support from the National Science Council through Grant NSC 102-2221-E-129-002-MY3 is gratefully acknowledged.

\section{References}

[1] L. Ke, H. Liu, M. Yang, Z. Jiao, X. Sun, Degradation analysis of Alq3based OLED from noise fluctuations with different driving modes, Chemical Physics Letters 623 (2015), p. 68-71.

[2] X. Wu, J. Liu, G. He, A highly conductive PEDOT:PSS film with the dipping treatment by hydroiodic acid as anode for organic light emitting diode, Organic Electronics 22 (2015), p. 160-165.

[3] A.R. Cho, E.H. Kim, S.Y. Park, L.S. Park, Flexible OLED encapsulated with gas barrier film and adhesive gasket, Synthetic Metals 193 (2014), p. 77-80.

[4] G. Liu, J.B. Kerr, S. Johnson, Dark spot formation relative to ITO surface roughness for polyfluorene devices, Synthetic Metals 144 (2004), p. 1-6.

[5] H. Ohta, M. Orita, M. Hirano, H. Hosono, Surface morphology and crystal quality of low resistive indium tin oxide grown on yittriastabilized zirconia, Journal of Applied Physics 91 (2002), p. 3547-3550.
[6] Y. Leterrier, L. Medico, F. Demarco, J.A.E. Manson, U. Betz, M.F. Escola, Mechanical integrity of transparent conductive oxide films for flexible polymer-based displays, Thin Sol Films 460 (2004), p. 156-66.

[7] T.P. Nguyen, P. Le Rendu, P.D. Long, S.A. De Vos, Chemical and thermal treatment of PEDOT:PSS thin films for use in organic light emitting diodes, Surface \& Coatings Technology 180 (2004), p. 646-649.

[8] T. Aernouts, P. Vanlaeke, W. Geens, J. Poortmans, P. Heremans, S. Borghs, Printable anodes for flexible organic solar cell modules, Thin Sol Films 451 (2004), p. 22-5.

[9] S.A. Carter, J.C. Scott,P.J. Brock, Enhanced luminance in polymer composite light emitting devices, Applied Physics Letter 71 (1997), p. $1145-1147$.

[10] B.W. Xiao, Y.F. Shang, M. Meng, C.N. Li, Enhancement of hole injection with an ultra-thin $\mathrm{Ag} 2 \mathrm{O}$ modified anode in organic light emitting diodes, Microelectronics Journal 36 (2005), p. 105-108.

[11] F.S. Li, Z.J. Chen, C.L. Liu, Q.H. Gong, Improvement in performance of organic light-emitting diodes by adjusting charge-carrier mobility in organic/inorganic hybrid hole transporting layer, Chemical Physics Letters 412 (2005), p. 331-335.

[12] G.F. Wang, X.M. Tao, R.X. Wang, Fabrication and characterization of OLEDs using PEDOT:PSS and MWCNT nanocomposites, Composites Science and Technology 68 (2008), p. 2837-2841

[13] T.C. Li, R.C. Chang, Improving the performance of ITO thin films by coating PEDOT:PSS, International Journal of Precision Engineering and Manufacturing-Green Technology 1 (2014), p. 329-334. 